\title{
Stilbene, Ellagic Acid, Flavonol, and Phenolic Content of Muscadine Grape (Vitis rotundifolia Michx.) Cultivars
}

\author{
Donna A. Marshall ${ }^{*}, 1$, Stephen J. Stringer ${ }^{1}$ and James D. Spiers ${ }^{2}$ \\ ${ }^{1}$ USDA-ARS Thad Cochran Southern Horticultural Laboratory, Poplarville, MS 39470, USA; ${ }^{2}$ Department of Horticul- \\ ture, Auburn University, Auburn AL 36849, USA
}

\begin{abstract}
Stilbene, ellagic acid, flavonol, and phenolic compounds were analyzed in 19 muscadine cultivars and 2 muscadine selections. Analysis was carried out on muscadine fruit skin, pulp and juice partitions. The major phenolics in muscadine juice, pulp and skins were identified by their retention times and characteristic spectra. Quantification was made by calibration curves of external standards for each of the analyzed compounds: trans and cis resveratrol, trans and cis piceid, ellagic acid, myricetin, quercetin and kaempferol. Free and total ellagic acid was observed in muscadine juice of eight cultivars, in amounts up to $54.0 \mu \mathrm{g} / \mathrm{g}$ in 'Ison' and $56.0 \mu \mathrm{g} / \mathrm{g}$ in 'Janet'. In the pulp, free ellagic acid was only observed in 3 cultivars, and total ellagic acid was observed in 8 cultivars in amounts up to $57.0 \mu \mathrm{g} / \mathrm{g}$ for 'Janet' and 77.0 $\mu \mathrm{g} / \mathrm{g}$ for 'Southland'. Also in pulp, trans-resveratrol was observed in two cultivars, 'Eudora' and 'Janet' in amounts of 0.9 $\mu \mathrm{g} / \mathrm{g}$ and $4.3 \mu \mathrm{g} / \mathrm{g}$ respectively. In muscadine skin, free and total ellagic acid, myricetin, quercetin and kaempferol were observed in all 21 cultivars analyzed and trans resveratrol was observed in all cultivars except 'Alachua'. Ellagic acid was the most abundant phenolic compound in muscadine grape skins. Total ellagic acid ranged from a low of $779.0 \mu \mathrm{g} / \mathrm{g}$ in 'Tara' to a high of 5,554.0 $\mu \mathrm{g} / \mathrm{g}$ in 'Southland'. The presence of ellagic acid and other nutraceutical compounds in muscadine grape could add value and marketability to the crop due to the possible health benefits. This southern specialty crop could fast become the next "super fruit".
\end{abstract}

Keywords: Muscadine, Nutraceutical, Piceid, polyphenolic, Resveratrol, Vitis rotundifolia.

\section{INTRODUCTION}

Muscadine grapes (Vitis Rotundifolia Michx.) are the most important Vitis species cultivated in the southeastern U.S. Muscadine grapes are native to the southeastern U.S., where vigorous vines grow to 30 meters in the wild. The grapes are considered a southern specialty, and have the potential for expanded markets in wine, juice, and health food production. They differ from other Vitis species in that muscadine grapes have an extra pair of chromosomes [1]. The fruit has a thicker skin than other Vitis species, which protects muscadines from heat, UV radiation, humidity, insects and fungi. Generally considered an underutilized commodity, muscadine grapes have a unique aroma and flavor that produces flavorful table wines. Muscadine grapes grow in small clusters and are especially important to the economy of southeastern states due to their resistance to Pierce's disease (Xylella fastidiosa) and generally thrive in soil and climate conditions not favorable for bunch grape production [2].

Muscadine grapes have several unique and distinguishing chemical characteristics, particularly the presence of ellagic acid. Ellagic acid is commonly present in other fruits, such as raspberry, strawberry, and blackberry, but is absent in all other Vitis species. Ellagic acid in muscadine grapes is

*Address correspondence to this author at USDA-ARS Thad Cochran Southern Horticultural Laboratory, Poplarville, MS 39470, USA; Tel: 601-403-8762; Fax: 601-795-4965;

E-mail: Donna.Marshall@ars.usda.gov expressed as free ellagic acid, ellagic acid glycosides, and ellagitannins [2]. The presence of ellagic acid and its derivatives in plants is of interest and has been widely studied because of its antiproliferative and antioxidant properties. The antiproliferative properties are due to its ability to directly inhibit DNA binding of certain carcinogens, including nitrosamines and polycyclic aromatic hydrocarbons (PAHs) [3]. Ellagic acid also has a chemoprotective effect in cellular models by reducing oxidative stress [2-7]. Ellagic acid and its derivatives are being aggressively investigated for chemoprevention. It has been demonstrated that extracts of fruits containing ellagic acid derivatives are more powerful than individual substances. This is because there are multiple phenolic substances in a fruit that can act synergistically with the ellagic acid compounds within the biological processes that involve cancer initiation and growth $[5,8,9]$. The presence of ellagic acid and quercetin in muscadine grape could add value and marketability to the crop due to the possible health benefits $[1,2]$.

Also unique to muscadine grapes is the presence of myricetin in the bronze grapes, as this flavonol is not present in white $V$. vinifera grapes [10]. Flavonols are extensively studied compounds found in muscadine grapes. In humans, protection against carcinogenesis is a widely documented effect of flavonols [11]. Quercetin, a flavonol, has been extensively studied, and has been shown to protect against DNA mutations, colon cancer and heart disease [12]. Quercetin relaxes the blood vessel wall [13] and increases the production of enzymes that dissolve blood clots [14]. Re- 
search has recently shown that ellagic acid combined with quercetin act together to affect the growth rate and the path by which cancer cells die. The combination of these two compounds changes the activity of regulatory proteins and enzymes called MAP kinases that regulate cell division and viability [8]. In a study of anticancer activities of muscadine grape phenolics, $50 \%$ inhibition of cancer cell population growth for colon cancer cell lines was observed at concentrations of $1-7 \mathrm{mg} / \mathrm{mL}$ of muscadine skin extracts [15]. Hudson [16] found that muscadine grape skin extract inhibited tumor cell growth in all transformed prostate cancer cell lines tested. The higher total phenolic content present in muscadine grapes compared to other Vitis species is attributed to high ellagic acid, gallic acid, and flavonoid glycoside concentrations $[2-5,17,18]$.

Phenylpropanoids, or phenolics are a large family of secondary metabolites involved in plant response to abiotic and biotic stresses. Phenolics are ubiquitous in the plant kingdom and are the most abundant secondary metabolites found in plants [19]. Many phenolics not only protect the parent plant, but also exhibit significant pharmacological benefits. Phenolic compounds play an important role in overall food properties, as they are generally involved in defense against ultraviolet radiation or as phytoalexins [19-22]. Phenolics may also play a role in the regulation of plant metabolism [23]. Polyphenols represent the third most abundant constituent in grapes and wines after carbohydrates and fruit acids [20]. Phenolics are mainly distributed as $28-35 \%$ in skin, $60-70 \%$ in seed and less than $10 \%$ in the pulp of the grape [24]. Phenolics contribute to the bitterness and astringency of fruits and are also considered to be the most important compounds affecting flavor and color differences in wines. Analysis of total phenolics is used to estimate the antioxidant capacities of fresh fruits and vegetables [25].

Stilbenes are a small class of phenylpropanoids characterized by a 1,2-diphenylethylene backbone. Stilbenes are synthesized in grape berries under natural environmental conditions $[26,27]$, but are increased by the up-regulation of defense genes encoding pathogenesis-related proteins [28]. The cis- and trans-isomers of resveratrol, a pharmacologically important stilbene, are present in the skin during all ripening stages, but are almost totally absent from the pulp [28]. Specific accumulation of resveratrol in the berry skin results from the localization of stilbene synthase (STS), the pivotal enzyme for stilbene biosynthesis. As a defense mechanism, stilbenes display potent antifungal effects as well as function in dormancy and growth inhibition in plants [29]. From a pharmacological perspective, scientists have been reporting for over a decade the various ways that the stilbene, resveratrol, can positively affect health [30-38]. Piceid, resveratrol 3-O- $\beta$-D-glucoside, also exhibits activity comparable to resveratrol [39]. Resveratrol and piceid exist in the cis form, which is an isomer of the trans form. In early studies trans-resveratrol (TRes) was shown to inhibit platelet aggregation, inhibit the oxidation of low-density lipoproteins, reduce the level of triacylglycerol and protect the liver from lipid peroxidation [39]. Since glycosidase is known to be present in the digestive tract, it is possible that piceid could be converted to resveratrol and absorbed during digestion [40]. Therefore it is important to consider all isomers and glucosides of TRes.
Another unique attribute of muscadine fruit chemistry is the present of anthocyanins as 3,5-diglucosides of delphinidin, cyanidin, petunidin, peonidin, and malvidin in nonacylated forms $[10,41,42]$. Though absorption of anthocyanins appears to be low in humans [43], it seems likely that cells in which they function in defense of oxidative stress must concentrate the anthocyanins or one of their derivatives $[44,45]$. Anthocyanins are known to protect blood vessels in humans. They also play a role in cancer prevention. There are more than 80 publications that discuss the ability of different anthocyanins to prevent different kinds of cancer [46].

As noted, much work has been done on health benefits of individual chemicals found in muscadine grapes, but thus far there has not been a study showing the concentrations of these compounds in a variety of muscadines. Most studies have only looked at a few muscadines varieties such as, 'Noble', 'Ison', and 'Carlos' because these are the most widely grown for production and wine aspects. A more comprehensive look at muscadine cultivars would reveal, some "hidden treasures" in lesser known cultivars.

This study was initiated to determine total phenolics and anthocyanins in whole muscadine grapes, as well as total ellagic acid, stilbenes and the flavonols present in juice, pulp and skin of 19 cultivars and two selections (Table 1) of muscadine grapes grown at the Thad Cochran Southern Horticultural Laboratory (TCSHL) in Poplarville, Mississippi. A comprehensive analysis of these compounds has not previously been reported for muscadine grapes in the gulf coast region, and would provide a valuable resource for growers in this area who are looking for muscadine cultivars that may possibly maximize the functional food benefit of their product.

\section{MATERIALS AND METHODS}

\section{Fruit Preparation and Storage}

All muscadine grape cultivars were collected from the McNeill, MS vineyard of the TCSHL in August of 2007. Approximately $4.5 \mathrm{~L}$ of fruit were randomly collected at the time of optimum harvest maturity. Homogeneous fruit subsamples were immediately separated into skins, seeds, juice and pulp. Berries were cut in half around the equator with a scalpel. Seeds were extracted and set aside. Berry halves were mashed gently to separate skin from juice and pulp. Juice partition was separated from pulp by hand squeezing through four layers of cheesecloth. Fruit parts were separated into three replications, lyophilized, then ground finely with a coffee grinder and stored at $-20^{\circ} \mathrm{C}$ until further analysis.

\section{Extraction and Analysis of Stilbene, and Free Ellagic Acid}

Samples of $1 \mathrm{~g}$ of lyophilized juice, pulp, or skin were put into centrifuge tubes with $10 \mathrm{~mL}$ of $80: 20$ ethanol:water [47]. Solutions were homogenized for $1 \mathrm{~min}$, and then incubated for $30 \mathrm{~min}$ at $60{ }^{\circ} \mathrm{C}$ with agitation every $5 \mathrm{~min}$ [47]. After heating, the tubes were removed and centrifuged at $1,000 \mathrm{rpm}$ for $15 \mathrm{~min}$. Supernatant was filtered through a fine mesh filter to remove the large particles and brought to a volume of $10 \mathrm{~mL}$ with 80:20 ethanol:water. An aliquot was then filtered in vacuo through a $0.2 \mu \mathrm{M}$ Nucleopore Track- 
Etch membrane (Milipore, Billerica, MA) and $1 \mathrm{~mL}$ was pipetted into sample vials for initial analysis by HPLC for free ellagic acid, ellagic acid glucosides, the stilbenes trans and cis resveratrol, and trans and cis piceid. HPLC analysis was carried out on a Dionex UVD 340S HPLC system (Dionex, Sunnyvale, CA) with a 4 channel diode array detector. The system was equipped with a Sunfire C18 column $5.0 \mu \mathrm{m}$ ODS (3.0 x $250 \mathrm{~mm})$ (Waters Corp, Milford, MA). The injection volume for both standards and samples was $20 \mu \mathrm{L}$. The flavonols and ellagic acid were quantified at $360 \mathrm{~nm}$, trans-compounds at $306 \mathrm{~nm}$ and the cis-compounds at 285 $\mathrm{nm}$. The mobile phase was solvent A, methanol/formic acid/water (10:1:89, v/v/v); solvent B, acetonitrile; and solvent $\mathrm{C}$, water. A multi-step gradient suitable for phenolic separation was used as follows: at 0 min, $100 \%$ solvent $A$; at $35 \mathrm{~min} 30 \%$ solvent $\mathrm{A}$ and $70 \%$ solvent $\mathrm{B}$; and at $50 \mathrm{~min}$ $100 \%$ solvent $\mathrm{C}$ with a $5 \mathrm{~min}$ postrun with solvent $\mathrm{C}$. The flow rate was $0.3 \mathrm{~mL} / \mathrm{min}$, which we determined to be necessary to achieve good peak separation. Samples were protected from light at all times to hinder degradation of the phenolic compounds and the conversion of cis-stilbenes to trans- isomers.

\section{Acid Hydrolysis for Flavonols and Total Ellagic Acid}

$2 \mathrm{~mL}$ of the previous sample were then added to $2 \mathrm{~mL}$ 2N HCL (166.66 mL 80:20 ethanol: water and $33.34 \mathrm{~mL}$ $\mathrm{HCl}$ ) and placed in a water bath for $60 \mathrm{~min}$ at $95^{\circ} \mathrm{C}$ to achieve acid hydrolysis of flavonoid glycosides to aglycons $[2,17]$. The samples were then vortexed for $30 \mathrm{sec}$ and refiltered in vacuo through a $0.2 \mu \mathrm{m}$ Nucleopore Track-Etch membrane and $1 \mathrm{~mL}$ was again pipetted into sample vials for final analysis by HPLC for flavonoids (myricetin, quercetin and kaempferol) and total ellagic acid. The HPLC analysis was carried out on the same system as above, using the same column, mobile phase and multi-step gradient program.

All compounds were identified by using UV/VIS spectral interpretation, and retention time of authentic standards (Sigma-Aldrich Chemical Co, St. Louis, MO). All external standards were prepared to 10,50 , and $100 \mathrm{ppm}$. Quantification was made by calculating the area under the curve based on calibration curves of external standards for each of the analyzed compounds, trans and cis resveratrol, cis piceid, ellagic acid, myricetin, quercetin and kaempferol. Detection limits are calculated by area under the curve of the standard: TRes - $1 \mu \mathrm{g} / \mathrm{g}$, EA - $10 \mu \mathrm{g} / \mathrm{g}$, myricetin, quercetin, kaemferol $-8 \mu \mathrm{g} / \mathrm{g}$, Cpic $-6 \mu \mathrm{g} / \mathrm{g}$. All results were expressed as $\mu \mathrm{g} / \mathrm{g}$ dry weight.

\section{Total Phenolics}

Total phenolics were identified by the Folin-Ciocalteau [48] assay with gallic acid equivalents. Fifty grams of previously frozen $\left(-20^{\circ} \mathrm{C}\right)$ fruit was blended to a fine puree, and filtered through cheesecloth. Filtered puree $(0.5 \mathrm{~g})$ was added to a $50 \mathrm{~mL}$ tube along with $25 \mathrm{~mL}$ of cold extraction solvent (4:4:2:0.001 acetone : methanol : deionized water : formic acid) and mixed thoroughly. Samples were filtered with \#4 Whatman filter paper (Fisher scientific, Waltham, MA), and two replications of $1.0 \mathrm{~mL}$ were each placed in a glass test tube. Folin-Ciocalteau reagent $(1.0 \mathrm{~mL})$ was added, mixed and allowed to stand for $3 \mathrm{~min}$. Then $1.0 \mathrm{~mL}$ of $1 \mathrm{~N}$ sodium carbonate was added, mixed and the sample was allowed to stand for $7 \mathrm{~min}$. Seven (7.0) $\mathrm{mL}$ water was added, mixed, capped and allowed to stand for $30 \mathrm{~min}$ at $40{ }^{\circ} \mathrm{C}$ in the dark [49] before reading the absorbance at $726 \mathrm{~nm}$ in a Beckman-Coulter DU 730 UV-VIS spectrophotometer (Beckman Coulter, Inc., Brea, CA). Total phenolic content was expressed in fresh weight as gallic acid equivalents in $\mathrm{mg} / 100 \mathrm{~g}$ sample, using a standard curve generated with 50, 100, 150, and $300 \mathrm{mg} / \mathrm{L}$ gallic acid.

\section{Total Anthocyanins}

Total anthocyanins were analyzed with a modified Giusti and Wrolstad [50] $\mathrm{pH}$ shift assay. Fifty (50.0) $\mathrm{g}$ of previously frozen fruit was blended to a fine puree, and filtered through cheesecloth. Filtered puree $(0.5 \mathrm{~g})$ was added to a 50 $\mathrm{mL}$ tube along with $25 \mathrm{~mL}$ of cold extraction solvent (4:4:2:0.001 acetone : methanol : deionized water : formic acid) and mixed thoroughly. Samples were filtered with \#4 Whatman filter paper, and $0.5 \mathrm{~mL}$ of each extracted sample was placed into $15 \mathrm{~mL}$ polypropylene tubes. Tubes consisted of 2 replications for $\mathrm{pH} 1.0$ and 2 replications for $\mathrm{pH} 4.5$. To adjust $\mathrm{pH} 4.5 \mathrm{~mL}$ of appropriate $\mathrm{pH}$ buffer was added. Tubes were capped, vortexed and allowed to stand for 30 minutes at $40^{\circ} \mathrm{C}$ [47] in the dark before reading the absorbance at 510 $\mathrm{nm}$ and $700 \mathrm{~nm}$ (to correct for haze) against a blank cell of distilled water in a Beckman-Coulter DU 730 UV-VIS spectrophotometer. The absorbance of the diluted sample (A) was as follows: $A=\left(A_{510}-A_{700}\right) \mathrm{pH} 1.0-\left(A_{510}-A_{700}\right) p H$ 4.5. The fresh weight anthocyanin content was then calculated as the total of monomeric anthocyanin pigment $(\mathrm{mg} / \mathrm{L})$ $=(\mathrm{A} \times \mathrm{MW} \times \mathrm{DF} \times 1,000) /(\varepsilon \times 1)$, where $\mathrm{A}$ is the absorbance of the diluted sample and DF is the dilution factor. MW and $\varepsilon$ refer to the predominant pigment content contained in the sample. For muscadine, cyanid-3-glucoside was used therefore MW $=449.2$ and $\varepsilon=26,900$.

\section{Statistical Analysis}

Data represents the mean of three replicate analyses by ANOVA to calculate $F$ probabilities. Mean separation achieved using LSD test $(\mathrm{P}<0.05)$ with SAS software 9.2 [51].

\section{RESULTS}

\section{Stilbene}

Trans resveratrol (TRes) was found in the skin of 20 of the 21 cultivars (Table $\mathbf{1}$ ).

TRes concentrations ranged from $0.0 \mu \mathrm{g} / \mathrm{g}$ in 'Alachua' to $66.0 \mu \mathrm{g} / \mathrm{g}$ in 'Pollyanna'. Of the 21 cultivars analyzed, 10 contained between 0.0 and $10.0 \mu \mathrm{g} / \mathrm{g}$ TRres, 4 contained between 10.0 and $20.0 \mu \mathrm{g} / \mathrm{g}$ and 6 contained between 20.0 and $35.0 \mu \mathrm{g} / \mathrm{g}$ TRes. Only one cultivar, 'Pollyanna' contained more than $34.35 \mu \mathrm{g} / \mathrm{g}$ TRes. TRes was only found in the pulp of 'Eudora' (0.948 $\mu \mathrm{g} / \mathrm{g})$ and 'Janet' (4.297 $\mu \mathrm{g} / \mathrm{g})($ Table 2) (Fig. 1).

TRes was not detected in the juice of any of the cultivars tested (Table 3). Finding resveratrol in the pulp of two cultivars is surprising, and could be significant. Resveratrol is not typically found in the pulp or juice of Vitis unless the juice is obtained by crushing the berry skin and seeds. 'Eudora' is a new cultivar recently released from the USDA. If resveratrol 
Table 1. Stilbene, Ellagic Acid, Flavonol Content in Skin of Muscadine Cultivars

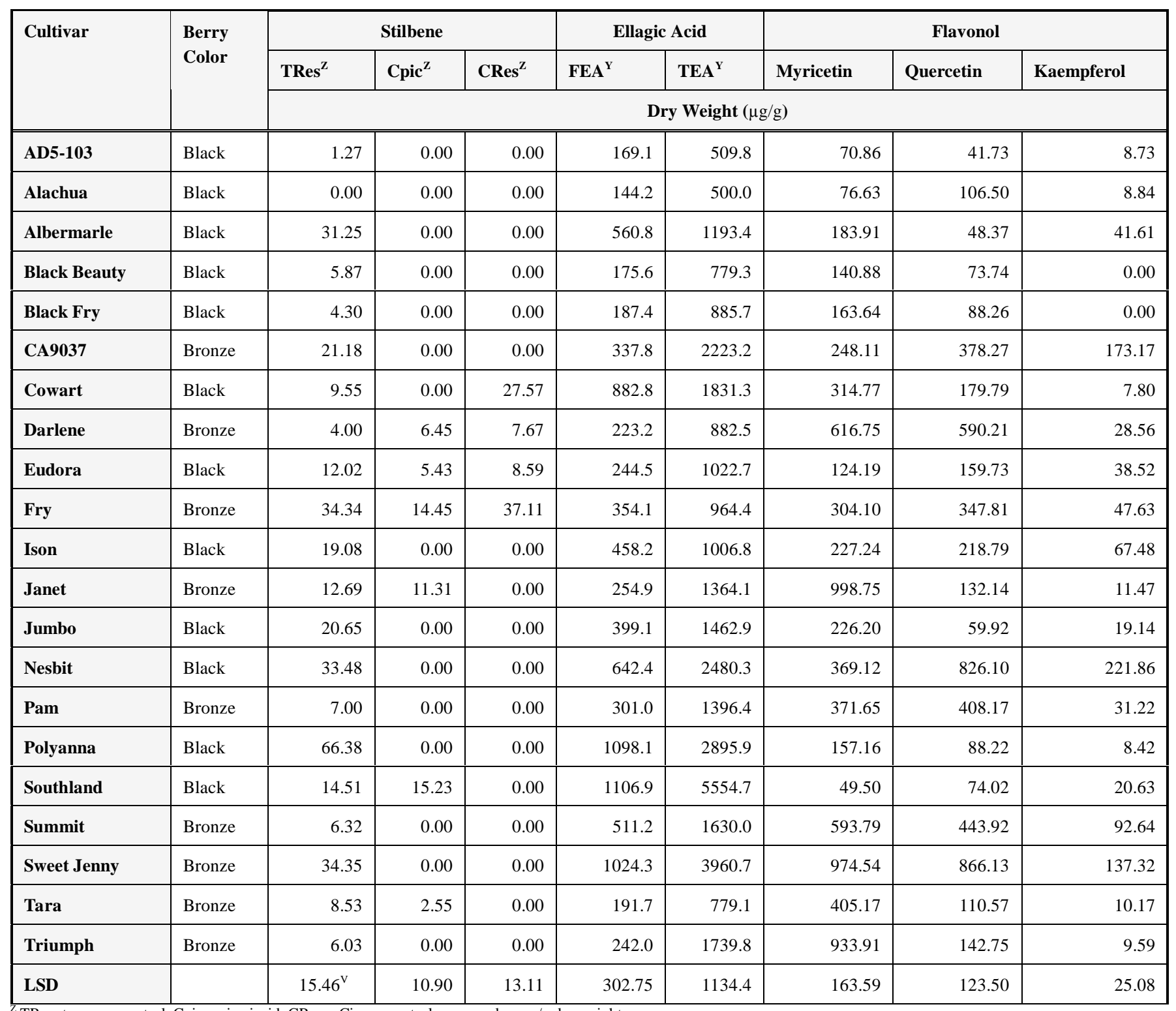

TRes=trans resveratrol, Cpic $=$ cis piceid, CRes $=$ Cis resveratrol expressed as $\mu \mathrm{g} / \mathrm{g}$ dry weight.

${ }^{\mathrm{Y}}$ FEA=Free Ellagic acid, TEA=Total Ellagic acid each expressed as $\mu \mathrm{g} / \mathrm{g}$.

${ }^{\mathrm{v}}$ Means Separation within columns by LSD P $\leqslant 0.05$ level.

in the pulp could be developed through breeding, it could greatly increase resveratrol consumption among muscadine consumers. In addition, cis piceid (Cpic) was found in the skin of only six cultivars and cis-resveratrol (CRes) was found in the skin of four cultivars. Three cultivars, 'Darlene', 'Eudora' and 'Fry' contained both CRes and Cpic. The greatest concentrations of Cpic were found in 'Southland' (15.23) and 'Fry' (14.45). CRes was highest in 'Fry' (37.11) and 'Cowart' (27.57), but was also found in 'Eudora' (8.59) and 'Darlene' (7.67). Of the cultivars tested TRes was not found equally in black $(18.19 \mu \mathrm{g} / \mathrm{g})$ and bronze $(14.94 \mu \mathrm{g} / \mathrm{g})$. This trend was also true of Cpic and CRes.

\section{Ellagic Acid}

Ellagic acid (EA) was the most abundant phenolic compound in muscadine grape skins (Table 1). Ellagic acid was found in all 21 cultivars in varying amounts. Fig. (2) shows the HPLC chromatograph of the recovery of ellagic acid, myrcetin, quercetin and kaempherol at $360 \mathrm{~nm}$. Free ellagic acid (FEA) was highest in 'Southland', 'Pollyanna', and 'Sweet Jenny' with $1,106.9 \mu \mathrm{g} / \mathrm{g}, 1098.1 \mu \mathrm{g} / \mathrm{g}$, and 1,024.3 $\mu \mathrm{g} / \mathrm{g}$ respectively. 'Alachua' had the least amount of FEA with $144.2 \mu \mathrm{g} / \mathrm{g}$. Total ellagic acid (TEA) ranged from a $5,554.7 \mu \mathrm{g} / \mathrm{g}$ in 'Southland' to a low of $500.0 \mu \mathrm{g} / \mathrm{g}$ in 'Alachua'. FEA was found in higher levels in the black $(505.80 \mu \mathrm{g} / \mathrm{g})$ cultivars than in the bronze $(382.2 \mu \mathrm{g} / \mathrm{g})$ of the cultivars tested, but this was not the case for the TEA where the black $(1,676 \mu \mathrm{g} / \mathrm{g})$ and bronze $(1,660 \mu \mathrm{g} / \mathrm{g})$ were much closer in concentration.

Total ellagic acid (TEA) was found in muscadine juice of eight cultivars, in amounts ranging from $24.201 \mu \mathrm{g} / \mathrm{g}$ in 'Darlene' to $56.765 \mu \mathrm{g} / \mathrm{g}$ in 'Janet' (Table 3). Of these, three cultivars also contained FEA: 'Pollyanna' (5.544), 'Fry' 
Table 2. Stilbene, Ellagic Acid, Flavonol Content in Pulp of Muscadine Cultivars

\begin{tabular}{|c|c|c|c|c|c|c|c|c|c|}
\hline \multirow[b]{3}{*}{ Cultivar } & \multirow{3}{*}{$\begin{array}{l}\text { Berry } \\
\text { Color }\end{array}$} & \multicolumn{3}{|c|}{ Stilbene } & \multicolumn{2}{|c|}{ Ellagic Acid } & \multicolumn{3}{|c|}{ Flavonol } \\
\hline & & $\operatorname{TRes}^{\mathrm{Z}}$ & Cpic & CRes & FEA $^{Y}$ & TEA $^{\mathbf{Y}}$ & Myricetin & Quercetin & Kaempferol \\
\hline & & \multicolumn{8}{|c|}{ Dry Weight ( $\mu \mathrm{g} / \mathrm{g})$} \\
\hline AD5-103 & Black & 0.00 & 0.00 & 0.00 & 0.00 & 0.00 & 0.00 & 0.00 & 0.00 \\
\hline Alachua & Black & 0.00 & 0.00 & 0.00 & 0.00 & 0.00 & 0.00 & 0.00 & 0.00 \\
\hline Albermarle & Black & 0.00 & 0.00 & 0.00 & 0.00 & 0.00 & 0.00 & 0.00 & 0.00 \\
\hline Black Beauty & Black & 0.00 & 0.00 & 0.00 & 0.00 & 0.00 & 0.00 & 0.00 & 0.00 \\
\hline Black Fry & Black & 0.00 & 0.00 & 0.00 & 14.57 & 46.22 & 0.00 & 0.00 & 0.00 \\
\hline CA9037 & Bronze & 0.00 & 0.00 & 0.00 & 0.00 & 35.94 & 0.00 & 0.00 & 0.00 \\
\hline Cowart & Black & 0.00 & 0.00 & 0.00 & 0.00 & 0.00 & 0.00 & 0.00 & 0.00 \\
\hline Darlene & Bronze & 0.00 & 0.00 & 0.00 & 0.00 & 0.00 & 0.00 & 0.00 & 0.00 \\
\hline Eudora & Black & 0.94 & 0.00 & 0.00 & 0.00 & 27.26 & 0.00 & 0.00 & 0.00 \\
\hline Fry & Bronze & 0.00 & 0.00 & 0.00 & 0.00 & 0.00 & 0.00 & 0.00 & 0.00 \\
\hline Ison & Black & 0.00 & 0.00 & 0.00 & 13.64 & 42.63 & 0.00 & 0.00 & 0.00 \\
\hline Janet & Bronze & 4.29 & 0.00 & 0.00 & 0.00 & 57.06 & 0.00 & 0.00 & 0.00 \\
\hline Jumbo & Black & 0.00 & 0.00 & 0.00 & 0.00 & 0.00 & 0.00 & 0.00 & 0.00 \\
\hline Nesbit & Black & 0.00 & 0.00 & 0.00 & 0.00 & 0.00 & 0.00 & 0.00 & 0.00 \\
\hline Pam & Bronze & 0.00 & 0.00 & 0.00 & 0.00 & 0.00 & 0.00 & 0.00 & 0.00 \\
\hline Polyanna & Black & 0.00 & 0.00 & 0.00 & 0.00 & 0.00 & 0.00 & 0.00 & 0.00 \\
\hline Southland & Black & 0.00 & 0.00 & 0.00 & 7.68 & 77.28 & 0.00 & 0.00 & 0.00 \\
\hline Summit & Bronze & 0.00 & 0.00 & 0.00 & 0.00 & 21.96 & 0.00 & 0.00 & 0.00 \\
\hline Sweet Jenny & Bronze & 0.00 & 0.00 & 0.00 & 0.00 & 40.18 & 0.00 & 0.00 & 0.00 \\
\hline Tara & Bronze & 0.00 & 0.00 & 0.00 & 0.00 & 0.00 & 0.00 & 0.00 & 0.00 \\
\hline Triumph & Bronze & 0.00 & 0.00 & 0.00 & 0.00 & 0.00 & 0.00 & 0.00 & 0.00 \\
\hline LSD & & $0.984^{\mathrm{V}}$ & 0.00 & 0.00 & 0.116 & 1.93 & 0.00 & 0.00 & 0.00 \\
\hline
\end{tabular}

${ }^{\mathrm{Z}}$ TRes=trans resveratrol, $\mathrm{Cpic}=$ cis piceid, $\mathrm{CRes}=$ Cis resveratrol expressed as $\mu \mathrm{g} / \mathrm{g}$ dry weight.

${ }^{\mathrm{Y}} \mathrm{FEA}=$ Free Ellagic acid, TEA=Total Ellagic acid each expressed as $\mu \mathrm{g} / \mathrm{g}$ dry weight.

${ }^{\mathrm{v}}$ Means Separation within columns by LSD P $\leq 0.05$ level.

(15.283) and 'Ison' (47.772). 'Darlene', 'Fry', and 'Pollyanna' had EA in juice (Table 3), but EA was not found in the pulp (Table 2). In the pulp, TEA was also found in 8 cultivars, five were common to the juice, but three had TEA only in the pulp ('Black Beauty', 'Black Fry' and 'Southland'). TEA was found ranging from $21.962 \mu \mathrm{g} / \mathrm{g}$ in 'Summit' to $77.275 \mu \mathrm{g} / \mathrm{g}$ in 'Southland'.

\section{Flavonol}

The most abundant flavonol contained in muscadine skins was found to be myricetin, followed by quercetin, then kaempferol. Bronze cultivars (BR), 'Janet', 'Sweet Jenny', and 'Triumph' (998.75 $\mu \mathrm{g} / \mathrm{g}, 974.54 \mu \mathrm{g} / \mathrm{g}, 933.91 \mu \mathrm{g} / \mathrm{g}$, respectively) were significantly higher in myricetin, followed by 'Darlene' and 'Summit' $(616.75 \mu \mathrm{g} / \mathrm{g}$ and 593.79 $\mu \mathrm{g} / \mathrm{g}$, respectively) which are also bronze. Black cultivars
(BL) did contain myricetin, but at lower levels. Quercetin was also found greatest in 'Sweet Jenny' (BR), and 'Nesbit' (BL), with $866.13 \mu \mathrm{g} / \mathrm{g}$, and $826.10 \mu \mathrm{g} / \mathrm{g}$, followed by 'Darlene' (BR) with 590.21 $\mu \mathrm{g} / \mathrm{g}$. Kaempferol was most abundantly present in 'Nesbit' (BL) with $221.86 \mu \mathrm{g} / \mathrm{g}$, followed by 'CA9037' (BR) with $173.17 \mu \mathrm{g} / \mathrm{g}$, then 'Sweet Jenny' (BR) with $137.32 \mu \mathrm{g} / \mathrm{g}$ and 'Summit' (BR) with $92.64 \mu \mathrm{g} / \mathrm{g}$. Levels of kaempferol decreased down to 0.00 $\mu \mathrm{g} / \mathrm{g}$ in 'Black Fry' and 'Black Beauty'. As with other polyphenolic compounds, there were no flavonols detected in the pulp or the juice of the muscadine cultivars tested.

\section{Phenolics and Anthocyanins}

Total phenolics in whole grapes (Table 4) ranged from $274.58 \mathrm{mg} / 100 \mathrm{~g}$ in 'Fry' to $1,061.65 \mathrm{mg} / 100 \mathrm{~g}$ in 'Nesbit'. Bronze cultivars averaged $405.23 \mathrm{mg} / 100 \mathrm{~g}$, significantly less than the black cultivars averaging $618.06 \mathrm{mg} / 100 \mathrm{~g}$. Antho- 


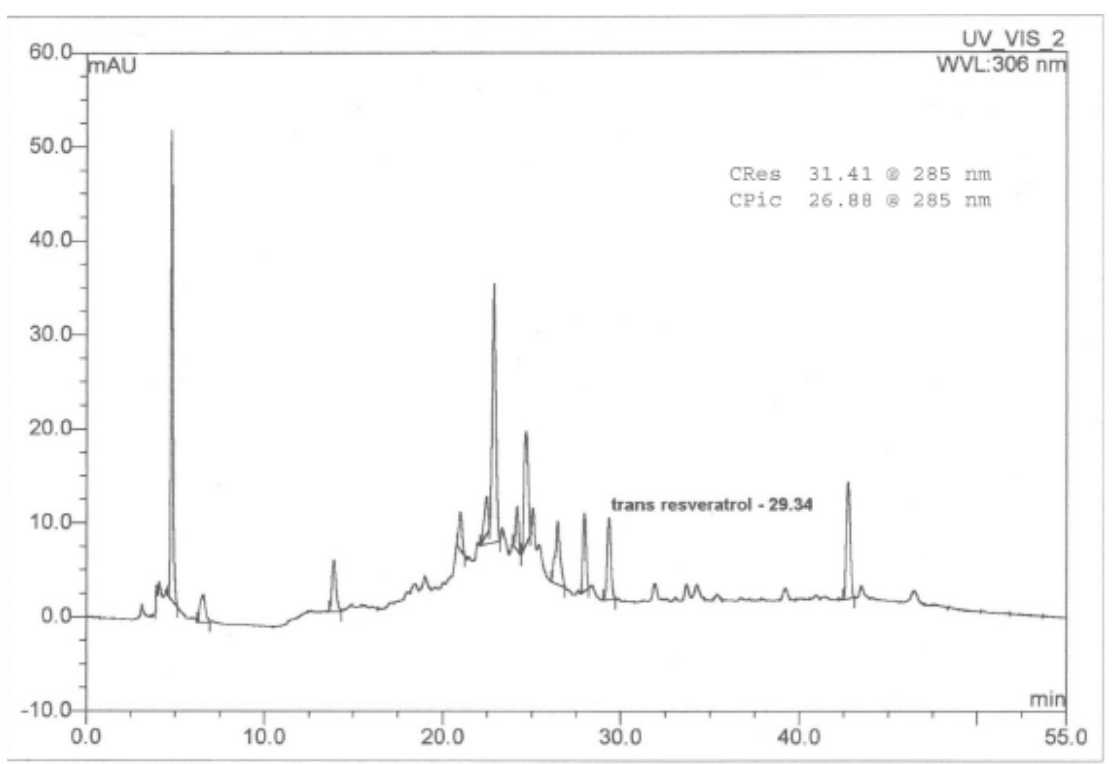

Fig. (1). HPLC chromatograph of pulp from 'Janet' muscadine at $306 \mathrm{~nm}$.

Table 3. Stilbene, ellagic acid, flavonol content in juice of muscadine cultivars

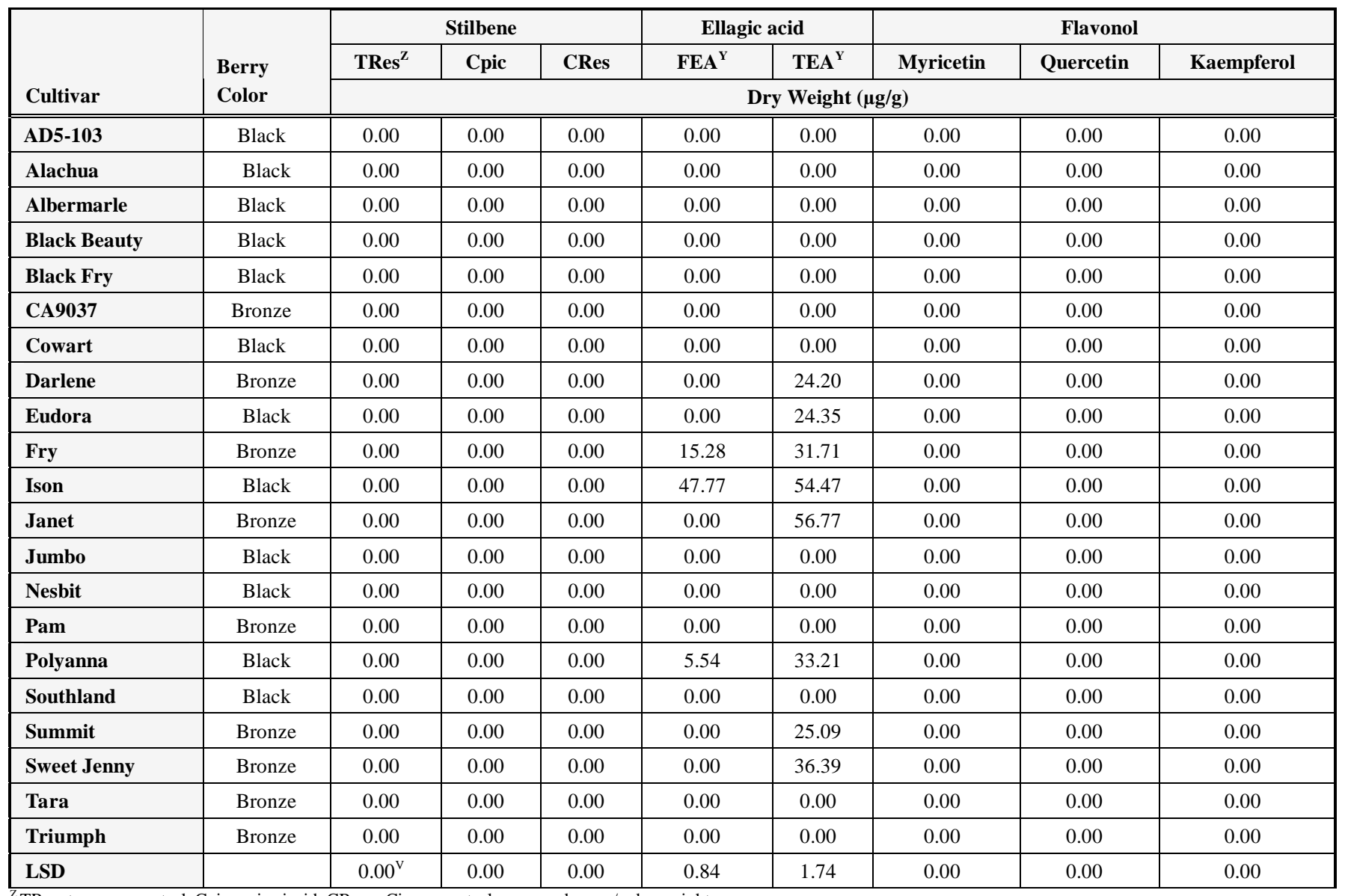

${ }_{\mathrm{Z}}^{\mathrm{Z}} \mathrm{TRes}=$ trans resveratrol, $\mathrm{Cpic}=$ cis piceid, CRes $=$ Cis resveratrol expressed as $\mu \mathrm{g} / \mathrm{g}$ dry weight.

${ }^{\mathrm{Y}} \mathrm{FEA}=$ Free Ellagic acid, TEA=Total Ellagic acid each expressed as $\mu \mathrm{g} / \mathrm{g}$ dry weight.

${ }^{\vee}$ Means Separation within columns by LSD P $\leqslant 0.05$ level.

cyanins ranged from 0 in the bronze skinned cultivars to $150.29 \mathrm{mg} / 100 \mathrm{~g}$ in 'Nesbit'. Anthocyanin followed the same trend as total phenolics where black cultivars $(58.875$ $\mathrm{mg} / 100 \mathrm{~g})$ had significantly higher levels than bronze cultivars $(0.643 \mathrm{mg} / 100 \mathrm{~g})$.

\section{DISCUSSION AND CONCLUSION}

This study has found that levels of ellagic acid, phenolics, and stilbenes in muscadine grape skins range greatly. Ellagic acid was found in the skins of all varieties tested. 


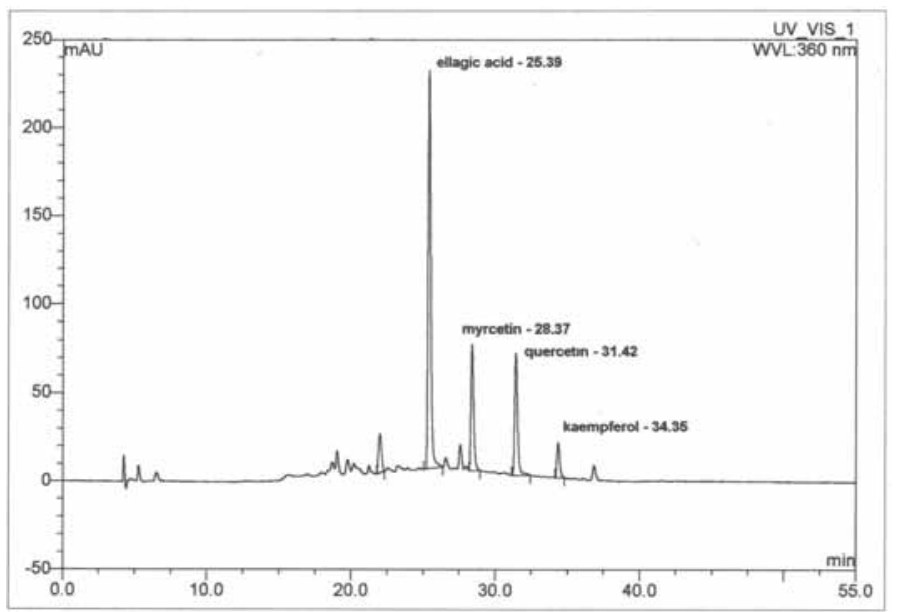

Fig. (2). HPLC Chromatograph of 'Eudora' skin. Ellagic acid, myrcetin, quercetin, and kaempferol peaks at $360 \mathrm{~nm}$.

Table 4. Anthocyanin and Total Phenolic Content in Whole Muscadine Grapes

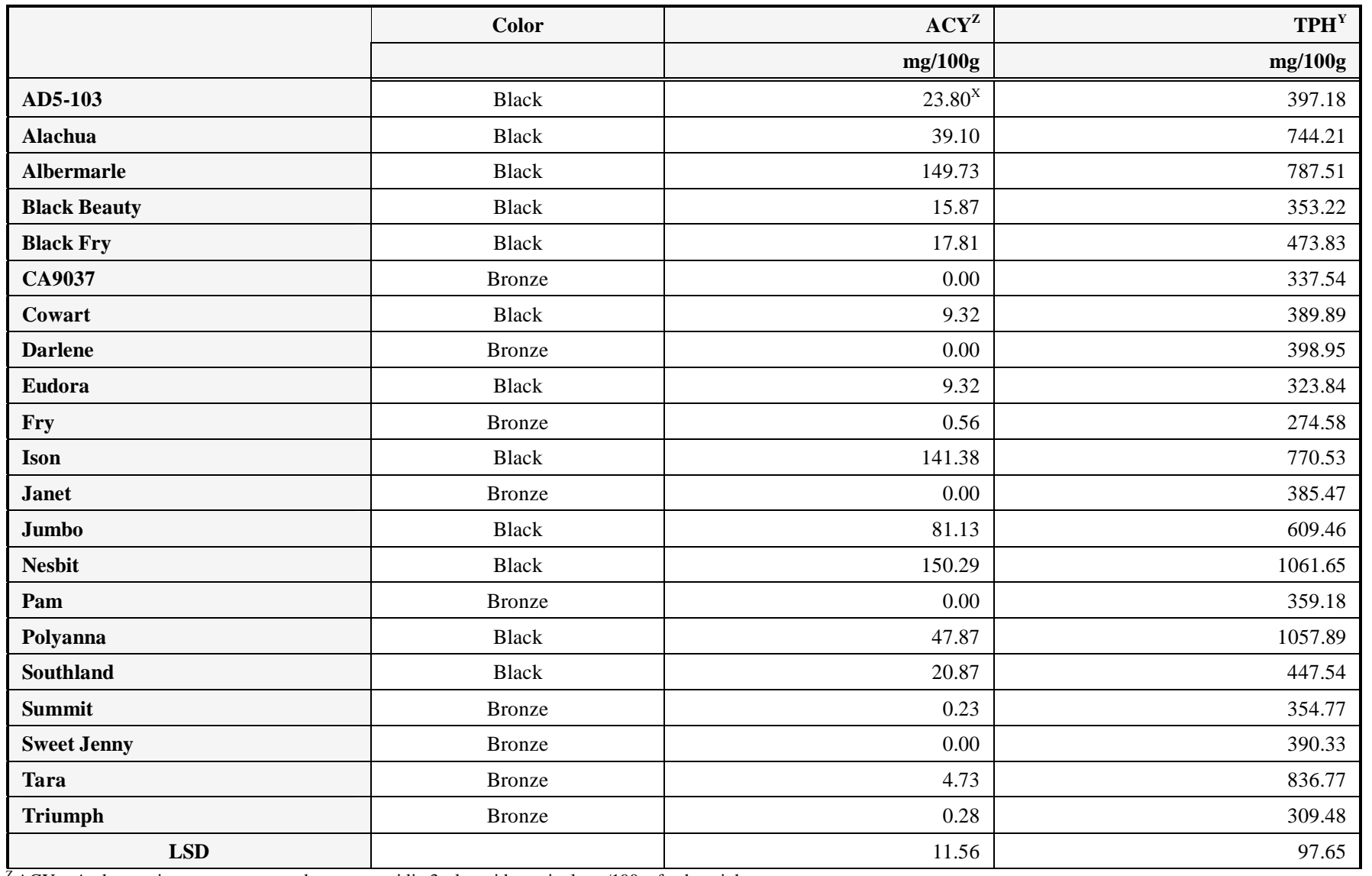

${ }^{\mathrm{z}} \mathrm{ACY}=$ Anthocyanin content expressed as $\mathrm{mg}$ cyanidin 3-glucoside equivalents $/ 100 \mathrm{~g}$ fresh weight.

${ }_{\mathrm{Y}}^{\mathrm{T}} \mathrm{TPH}=$ Total phenolic content expressed as mg gallic acid equivalent/100 $\mathrm{g}$ fresh weight.

${ }^{\mathrm{X}}$ Means Separation within columns by LSD P $\leq 0.05$ level.

This information can be used by muscadine geneticists to develop a healthier berry. Also, the presence of resveratrol in the pulp of 'Eudora'; and 'Janet' opens up possibilities of breeding for nutraceutical benefits as well. Typically muscadine geneticists select for sweetness, firmness, skin thickness, disease resistance, and other attributes that are visual or palatable. These and other performance characteristics for many of the cultivars in this study are detailed in a previous study [52]. Yet, with an ever increasing drive for healthier foods, this current study shows that muscadines are a "hid- den treasure". Muscadine grapes are a unique member of the Vitis genus. The presence of ellagic acid and high total phenolic content, and resveratrol make it an undiscovered superfurit. Black muscadines did contain higher levels of total phenolic than the bronze berries. This suggests that the black berries would contain a higher antioxidant capacity. Interestingly though, the TRes concentrations were not influenced by skin color. Bronze berries had equally as much resveratrol as did the black berries within the cultivars tested. 
One note to remember, the muscadine berries were carefully cut and separated; therefore, juice partition was not obtained by crushing with seeds and skins as commonly done in commercial juice or wine production. If juice were obtained from crushing with skins and/or seeds, the juice would assumingly contain higher levels of compounds found in other studies [19]. Seed partitions are not reported. Literature $[4,39]$ states that the majority of the phenolic compounds in muscadines are found in the skins and seeds. Yet, the compounds found in seeds are different than those found in skin. Seed partitions contain gallic acid, catechin and epicatechin [4] which this study did not address.

Muscadine grapes are seeded grapes. Muscadines contain 3-6 large seeds in the center of the pulp. Yet, the nutraceutical benefits that consumers will obtain from the consumption of muscadine far exceed the inconvenience of removing seeds. Many fruit must be first peeled, cut, or somehow prepared for eating, muscadines are no different. With the combination of ellagic acid, resveratrol, and flavonols such as quercetin and myrcetin, muscadine grapes are a healthy choice for a whole food snack.

\section{ABBREVIATIONS}

$\begin{array}{ll}\text { ACY } & =\text { Anthocyanin } \\ \text { BL } & =\text { Black } \\ \text { BR } & =\text { Bronze } \\ \text { Cpic } & =\text { Cis-piceid } \\ \text { CRes } & =\text { Cis-resveratrol } \\ \text { FEA } & =\text { Free ellagic acid } \\ \text { GAE } & =\text { Gallic acid equivalent } \\ \text { PAH } & =\text { Polycyclic aromatic hydrocarbons } \\ \text { STS } & =\text { Stilbene synthase } \\ \text { TCSHL } & =\text { Thad Cochran Southern Horticultural } \\ \text { TEA } & =\text { Laboratory } \\ \text { TPH } & =\text { Total ellagic acid } \\ \text { TRes } & =\text { Trans-resveratrol }\end{array}$

\section{CONFLICT OF INTEREST}

None declared.

\section{ACKNOWLEDGEMENT}

None declared.

\section{REFERENCES}

[1] Patel, G.I.; Olmo, H.P. Cytogenetics of Vitis. I. The hybrid V. vinifera $x$ V. rotundifolia. Amer. J. Botany, 1955, 42, 141-155.

[2] Talcott, S.T.; Lee, J. Ellagic Acid and Flavonoid antioxidant content of Muscadine Wine and Juice. J. Agric. Food Chem., 2002, 50, 3186-3192.

[3] Lesca, P. Protective effects of ellagic acid and other plant phenols on benzo[a]pyrene-induced neoplasia in mice. Carcinogensis, 1983, 4, 1651-1653.

[4] Patrana-Bonilla, E.; Akoh, C. C.; Sellappan, S.; Krewer, G. Phenolic content and antioxidant capacity of muscadine grapes. J. Agric. Food Chem., 2003, 51, 5497-5503.
[5] Mertens-Talcott, S.U.; Talcott, S.T.; Percival, S.S. Low concentrations of quercetin and ellagic acid synergistically influence proliferation, cytotoxicity and apoptosis in MOLT,4 human leukemia cells. J. Nutr., 2003, 133, 2669-2674.

[6] Stoner, G.D.; Morse, M.A. Isothiocyanates and plant polyphenols as inhibitors of lung and esophageal cancer. Cancer Lett., 1997, 114, 113-119.

[7] Khanduja, K.L.; Gandhi, R.K.; Pathania, V.; Syal, N. Prevention of $N$-nitrosodiethylamine-induced lung tumorigenesis by ellagic acid and quercetin in mice. Food Chem. Toxicol., 1999, 37, 313-318.

[8] Mertens-Talcott S.U.; Percival, S.S. Ellagic acid and quercetin interact synergistically with resveratrol in the induction of apoptosis and cause transient cell cycle arrest in human leukemia cells. Cancer Lett., 2005, 218, 141, 151.

[9] Mertens-Talcott, S.U.; Bomser, J.A.; Romero, C.; Talcott, S.T.; Percival, S.S. Ellagic acid potentiates the effect of quercetin on p21(WSF1/CIP1), p52, and MAP-kinases without affecting intracellular generation of reactive oxygen species in vitro. J. Nutr., 2005, 135, 609-614.

[10] Flora, L.F. Influence of heat, cultivar and maturity on the anthocyanin-3,5-diglucosides of muscadine grapes. J. Food Sci., 1978, 43, 1819-1821.

[11] Williamson, G.; Manach, C. Bioavailability and bioefficacy of polyphenols in humans. II. Review of 93 intervention studies. Am. J. Clin. Nutr., 2005, 81, 243-255.

[12] Hollman, P.C.; Katan, M.B. Health effects and bioavailability of dietary flavonols. Free Radic.Res., 1999, 31 Suppl., S75-80.

[13] Rendig, S.V.; Symons, J.D.; Longhurst, J.C.; Amsterdam, E.A. Effects of red wine, alcohol and quercetin on coronary resistance and conductance arteries. J. Cardiovasc. Pharmacol., 2001, 38, 219-227.

[14] Abou-Agag L.H.; Aikens, M.L.; Tavengwa, E.M.; Benza, R.L.; Shows, S.R.; Grenett, H.E.; Booyse. F.M. Polyphyenolics increase t-PA and u-PA gene transcription in cultured human endothelial cells. Alcohol Clin. Exp. Res., 2001, 25, 155-162.

[15] Yi, W.; Fischer, J.; Akoh, C.C. Study of Anticancer activities of Muscadine Grape phenolics in vitro. J. Agric. Food Chem., 2005, $53,8804-8812$.

[16] Hudson, T.S.; Hartle, D.K.; Hursting, S.D.; Nunez, N.P.; Wang, T.T.Y.; Young, H.A.; Arany, P.; Green, J.E. Inhibition of Prostate cancer growth by Muscadine Grape Skin extract and resveratrol through distinct mechanisms. Cancer Res., 2007, 67, 8396-8405.

[17] Lee, J.H.; Talcott, S. T. Fruit maturity and juice extraction influences ellagic acid derivatives and other antioxidant polyphenolics in muscadine grapes. J. Agric. Food Chem., 2004, 52, 361-366.

[18] Yilmaz, Y.; Toledo, R.T. Major flavonoids in grape seeds and skins. Antioxidant capacity of catechin, epicatechin and gallic acid. J. Agic. Food Chem., 2004, 52, 255-260.

[19] Amakura, Y.; Umino, Y.; Tsuji, S.; Tonogai, Y. Influence of jam processing on the radical scavenging activity and phenolic content of berries. J. Agric. Food Chem., 2000, 48, 6292-6297.

[20] Singleton, V.L. Grape and wine phenolics: background and prospects. In Proceedings of the University of California, Davis, Grape and Wine Centenary Symposium, University of California, Davis, 1980, pp. 215-227.

[21] Zaat, S.A.J.; van Brussel, A.A.N.; Tak, T. Flavonoids induce Rhizobium leguminosaru to produce nodDABC gene-related factors that cause thick, short roots and root hair responses on common vetch. J. Bacteriol., 1987, 169, 3388-3391.

[22] Dixon, R.A. The phytoalexin response: elicitation, signaling and control of host gene expression. Biol. Rev., 1986, 61, 239-291.

[23] Laks, P.E.; Pruner, M.S. Flavonoid biocides: structure/activity relations of flavonoid pytoalexin analogues. Phytochemistry, 1989, 28, 87-91.

[24] Shi J.; Yu, J.; Pohorly, J.E.; Kakuda, Y. Polyphenolics in grape seeds- biochemistry and functionality. J. Med. Foods, 2003, 6, 291299.

[25] Thaipong, K.; Boonprakob, U.; Crosby, K.; Cisneros-Zevallos, L.; Byrne, D.H. Comparison of ABTS, DPPH, FRAC, and ORAC assays for estivating antioxidant activity from guava fruit extracts. $J$. Food Comp. Anal., 2006, 19, 669-675.

[26] Jeandet, P.; Bessis, R.; Gautheron B. The production of resveratrol (3,5,4'-trihydroxystilbene) by grape berries in different development stages. Am. J. Enol. Vitic., 1991, 42, 41-46.

[27] Vesari, A.; Parpinello, G.P; Tonmielli, G.B.; Ferrarini, R.; Giulivo, C. Stilbene compounds and stilbene sythase expression during rip- 
ening, wilting, and UV treatment in grape cv. Corvina. J. Agric Food Chem., 2001, 49, 5531-5536.

[28] Chong, J.; Poutaraud, A.; Hugueney, P. Metabolism and roles of stilbenes in plants. Plant Sci., 2009, 177, 143-155.

[29] Croteau, R.; Kutchan, T.M.; Lewis, N.G.; Natural Products (Secondary Metabolites) In Biochemistry and Molecular Biology of Plants; Buchanan, B.; Gruissem, B.; Jones, R., Eds; Rockville, MD. 2000. pp. 1309-1310.

[30] Arichi, H.; Kimura, Y.; Okuda, H.; Baba, K.; Kozawa M.; Arichi, S. Effects of stilbene components of the roots of Polygonum cuspidatum Sieb. et Zucc. on lipid metabolism. Chem. Pharm. Bull., 1982, 30, 1766-1770.

[31] Brakenhielm, E.; Cao, R.; Cao, Y. Suppression of angiogenesis, tumor growth and wound healing by resveratrol a natural compound I red wine and grapes. FASEB J., 2001, 15, 1798-1800.

[32] DeSanti, C.; Pietrabissa, A.; Spisni, R.; Mosca, F.; Pacifici, G. Sulphation of resveratrol, a natural compound present in wine, and its inhibition by natural flavonoids. Xenobiotica, 2000a, 30, 857866.

[33] DeSanti, C., Pietrabissa, A.; Spisni, R.; Mosca, F.; Pacifici, G. Glucuronidation of resveratrol, a natural compound present in wine, in the human liver. Xenobiotica, 2000b, 30, 1047-1054.

[34] El-Mowafy, A. Resveratrol activates membrane-bound guanylyl cyclase in coronary arterial smooth muscle: A novel signaling mechanism in support of coronary protection. Biochem. Biophys. Res. Commun., 2002, 291, 1218-1224.

[35] Jang, M.; Lining, C; Udeani, G.; Slowing, K.; Thomas, C; Beecher, C.; Fong, H.; Farnsworth, N.; Kinghorn, A.; Mehta, R.; Moon, R.; Pozzuto, J. Cancer chemopreventative activity of resveratrol, a natural product derived from grapes. Science, 1997, 275, 218-220.

[36] Kimura, Y.; Okuda, H.; Arichi, S. Effects of stilbene on arachidonate metabolism in leukocytes. Biochim. Biophys. Acta., 1985, 834, 275-278.

[37] Kinsella, J.; Frankel, E.; German, B.; Kanner, J. Possible mechanisms for the protective role of antioxidants in wine and plant foods. Food Technol., 1993, 47, 85-90.

[38] Lu, R; Sorreno, G. Resveratrol, a natural product derived from grapes, exhibits antiestrogenic activity and inhibits the growth of human breast cancer cells. J. Cell. Physiol., 1999, 197, 297-304.

[39] Romero-Pérez, A.I.; Ibern-Gómez, M.; Lamuela-Raventós, R.M.; Carmen de la Torre-Boronat, M. Picied, the Major Resveratol Derivative in Grape Juices. J. Agric. Food Chem., 1999, 47, 15331536.

[40] Hackett, A. The metabolism of flavanoid compounds in mammals. plant flavanoids. In: Biology and Medicine: Biochemical, Pharma- cological and Structure-Activity Relationships: Proceedings. Buffalo, NY. July V. Cody, E. Middleton and J Harbone Eds, 1986, Pp. 177-194.

[41] Goldy, R.G.; Ballinger, W.E.; Maness, E.P. Fruit anthocyanin content of some Euvitis x vitis rotundifolia hybrids. J. Am. Soc. Hort. Sci., 1986, 111, 955-960.

[42] Lamikanra, O. Development of anthocyanin pigments in muscadine grapes. Hort. Sci., 1988, 23, 591-599.

[43] Prior R.L. Absorption and Metabolism and Anthocyanin: Potential Health Effects. In: Phytochemicals: Mechanisms of Action. Edited by Meskin MS, Bidlack, W.R., Davies, A.J., Lewis D.A. Randolph, R.K.; Eds. Boca Raton: CRC Press, 2004, pp. 1-19.

[44] Galli, R.L.; Bielinski, D.F.; Szprengiel, A.; Shukitt-Hale, B.; Joseph, J.A. Blueberry supplemented diet reverses age-related decline in hippocampal HSP70 neuroprotection. Neurobiol. Aging, 2006, 27, 344-350.

[45] Galli, R.L.; Shukitt-Hale, B.; Youdim, K.A.; Joseph, J.A. Fruit polyphenolics and brain aging: nutritional interventions targeting age related neuronal and behavioral deficits. Ann. NY. Acad Sci. 2002, 959, 128-132.

[46] Hartle, D.K.; Greenspan, P.; Hargrove, J.L. Muscadine Medicine. Blue Heron Nutraceuticals, 2005.

[47] LeBlanc, M. Cultivar, Juice Extraction, Ultra Violet Irradiation and Storage Influence the Stilbene Content of Muscadine Grape (Vitis rotundifolia Michx.). Dissertation Department of Horticulture. Louisiana State University, 2006.

[48] Singleton, V.L.; Rossi, J.A. Jr. Colorimetry of total phenolics with phosphomolybdic-phosphotungstic acid reagents. Am. J. Enol. Vitic., 1965, 16, 144-158.

[49] Waterhouse, A. L. Determination of total phenolics. In Current Protocols in Food Analytical Chemistry; Wrolstad, R. E., Ed.; John Wiley \& Sons: New York, 2002; units I.1.1.1-I1.1.8

[50] Giusti, M.M.; Wrolstad, R.E. Characterization and measurement of anthocyaninis by UV-visible spectroscopy. In Current Protocols in Food Analytical Chemistry: Wrolstad, R.E., Accree, T.E., An, H., Decker, E.A., Penner, M.H., Reid, D.S., Schwartz, S.J., Shoemaker, C.F., Sporns, P., Eds.; Wiley: New York, 2001, pp. F1.2.1F1.2.13.

[51] SAS. 2008. SAS Institute Inc., Copyright 2002. Cary, North Carolina, USA.

[52] Stringer, S.J.; Marshall, D.A.; Sampson, B.J.; Spiers, J.M. Performance on muscadine grape cultivars in southern Mississippi. Hort. Technol., 2008, 18, 726-733.

(C) Marshall et al.; Licensee Bentham Open.

This is an open access article licensed under the terms of the Creative Commons Attribution Non-Commercial License (http://creativecommons.org/ licenses/ by-nc/3.0/) which permits unrestricted, non-commercial use, distribution and reproduction in any medium, provided the work is properly cited. 